Georgia State University

ScholarWorks @ Georgia State University

2010

\title{
Trust with Private and Common Property: Effects of Stronger Property Right Entitlements
}

James C. Cox

Georgia State University, jccox@gsu.edu

Daniel T. Hall

High Point University, dhall@highpoint.edu

Follow this and additional works at: https://scholarworks.gsu.edu/econ_facpub

Part of the Economics Commons

\section{Recommended Citation}

Cox, James C.; Hall, Daniel T. 2010. "Trust with Private and Common Property: Effects of Stronger Property Right Entitlements." Games 1, no. 4: 527-550.

This Article is brought to you for free and open access by the Department of Economics at ScholarWorks @ Georgia State University. It has been accepted for inclusion in ECON Publications by an authorized administrator of ScholarWorks@ Georgia State University. For more information, please contact scholarworks@gsu.edu. 
Article

\title{
Trust with Private and Common Property: Effects of Stronger Property Right Entitlements
}

\section{James C. Cox ${ }^{1, *}$ and Daniel T. Hall ${ }^{2}$}

1 Georgia State University, Experimental Economics Center and Department of Economics, 14 Marietta Street, P.O. Box 3992, Atlanta, GA 30302, USA

2 High Point University, Phillips School of Business, Drawer 40, 833 Montlieu Avenue, High Point, NC 27262, USA; E-Mail: dhall@highpoint.edu

* Author to whom correspondence should be addressed; E-Mail: jccox@gsu.edu.

Received: 15 September 2010; in revised form: 15 October 2010 / Accepted: 8 November 2010 / Published: 10 November 2010

\begin{abstract}
Is mutually beneficial cooperation in trust games more prevalent with private property or common property? Does the strength of property right entitlement affect the answer? Cox, Ostrom, Walker, et al. [1] report little difference between cooperation in private and common property trust games. We assign stronger property right entitlements by requiring subjects to meet a performance quota in a real effort task to earn their endowments. We report experiment treatments with sequential choice and strategy responses. We find that cooperation is lower in common property trust games than in private property trust games, which is an idiosyncratic prediction of revealed altruism theory [2]. Demonstrable differences and similarities between our strategy response and sequential choice data provide insight into the how these protocols can yield different results from hypothesis tests even when they are eliciting the same behavioral patterns across treatments.
\end{abstract}

Keywords: trust game; private property; common property; real effort; revealed altruism theory; strategy method; sequential choice 


\section{Introduction}

Cox, Ostrom, Walker, et al. [1], henceforth COW, addressed notions that common property is typically over-extracted, neglected, and abused. Predictions of such "tragedies of the commons" are often based on reasoning that confounds common property, per se, with open access common property [3]. COW reports an experiment with two payoff-equivalent 2-person sequential games: the private property trust game and the common property trust game. Both games are designed to measure the generosity of the first mover and the cooperative response of the second mover. The games differ only in the initial assignment of endowments as private or common property. COW reports no significant differences between private property and common property games for either first mover generosity or second mover cooperation in using data from a sequential choice experiment on subjects with unearned endowments. We investigate whether these results are robust to assigning stronger property right entitlements either with sequential choice or strategy responses by second movers. We assign stronger property right entitlements by requiring subjects to meet a performance quota in a real effort task to earn their private or common property endowments in our earned endowment treatments. This experiment design change reveals some new insights about behavior in private and common property environments. We find that a prediction of revealed altruism theory [2], that cooperation will be lower in the common property game, is confirmed under stronger property right entitlements, most clearly with data from the strategy response treatments. This same pattern in the data is inconsistent with all of the purely distributional models of social preferences including the Fehr and Schmidt [4], Bolton and Ockenfels [5], Charness and Rabin [6], and Cox and Sadiraj [7] models; for these models, the private and common property trust games are isomorphic.

Section 2 describes the private and common property trust games and the related theoretical predictions. Section 3 discusses the COW study design and results. Section 4 discusses the potential impact of stronger property right entitlements. Section 5 presents our experiment design with a real effort task. Section 6 reports results from our treatments that use the strategy method for eliciting second mover decisions. We find that second mover cooperation is lower in the common property game than in the private property game. Section 7 addresses the possibility that the results could be driven by the strategy method rather than the real effort task. This motivates our use of the sequential choice protocol (used in COW) to elicit second mover data in additional treatments. We find similar results for second mover behavior with our sequential choice and strategy method treatments. Another interesting finding is that first mover choices are different between the strategy method and sequential choice treatments (for eliciting second mover responses). In the sequential choice treatment, first movers make more choices at the extremes of "full trust" and "no trust" in the common property game than in the private property game, as though they anticipate the type of second mover choices that we observe.

\section{Theory}

The private property trust (PPT) game and the common property trust (CPT) game are both derived from the investment game [8]. In the investment game, there is a first mover and a second mover who interact in a one-shot game. Both start with an endowment of \$ 10 as their private property. The second mover is constrained to keep her \$ 10 endowment whereas the first mover can choose to send 
none, some, or all of her $\$ 10$ (in multiples of \$ 1) to the second mover. Each dollar sent by the first mover is tripled by the experimenters and added to the private endowment of the second mover. Sending money creates a surplus which the second mover must then decide whether or not to share. A maximum surplus of \$ 20 is generated when the first mover sends his entire endowment of \$10. The second mover can return to the first mover any amount (in whole dollars) less than or equal to the amount received. The amount sent by the first mover is traditionally interpreted as a measure of the level of trust in the second mover. The amount returned is traditionally interpreted as a measure of the level of the second mover's positive reciprocity. However, Cox [9] showed that first mover and second mover actions can be partially motivated by unconditional altruism by using first mover and second mover dictator controls for the investment game. Still, we use the traditional label when we refer to decisions of "full trust" and "no trust" made in the PPT and CPT games.

The 2-person PPT game is different from the original investment game [8] in only one way: the second mover can return none, some, or all of her \$ 10 endowment in addition to the tripled amount received from the first mover if she wishes to do so. This change is necessary to make comparisons with the CPT game possible because the second mover is not required to withdraw any of the (\$40) common property. The 2-person CPT game is the "inverse" version of the PPT game. In the CPT game, \$ 40 (the maximum amount that can be generated for subject pairs in the investment game and 2-person PPT game) is assigned as the amount of common property endowment. The common property is described as a "joint decision fund" both subjects can withdraw from. The first mover can withdraw up to $\$ 10$, in whole dollar amounts, from the joint fund and place it into his private fund. Each dollar withdrawn by the first mover reduces the joint fund by $\$ 3$. The second mover's decision is how to divide the remaining joint fund between her private fund and the paired first mover's private fund after the first mover's decision.

The 2-person PPT game and the 2-person CPT game are strategically equivalent (or isomorphic) games according to the self-regarding preferences (or “economic man”) special case interpretation of game theory. The subgame perfect Nash equilibrium is the same for both games: the second mover will return none (allocate none) of his private fund (remaining joint fund) to the first mover, and the first mover, expecting this, will send nothing to the second mover (withdraw the maximum of \$ 10 from the joint fund). The investment game, PPT game, and CPT game all have the same subgame perfect Nash equilibrium for economic man game theory. However, deviations from this prediction have been observed in many experiments with the investment game including those reported in [8,9].

New theory has been developed to model social preferences in order to account for deviations from the predictions of economic man game theory in many "fairness games" [4-7]. These theories also predict that the PPT game and CPT game are isomorphic because they model unconditional preferences over the final distribution of payoffs amongst the set of distributions available. A first mover who sends an amount $\pi$ to the second mover in the PPT game or withdraws an amount $10-\pi$ in the CPT game provides the second mover with the same feasible set of ordered pairs of (first mover, second mover) money payoffs. Hence models of unconditional other-regarding preferences such as [4-7] predict that, for any given number of dollars sent in the PPT game or left (i.e., not withdrawn) in the CPT game, a second mover will return or allocate the same amount to the first mover in the PPT and CPT games. 
According to revealed altruism theory [2] these games are not isomorphic. That theory was developed to model both unconditional other-regarding preferences and reciprocity. The theory allows for individual preferences to include other players' earnings as well as their own earnings and it includes self-regarding (or "economic man”) preferences as a special case. Other-regarding preference ordering $A$ is more altruistic than preference ordering $B$ if preferences $A$ exhibit higher willingness to pay to increase another's material payoffs than do preferences $B$ ([2], p. 34). (Preference orderings $A$ and $B$ can represent the preferences of two different people or the preferences of the same person in two different situations.) Revealed altruism theory also provides a partial ordering of the generosity of opportunity sets that the first mover can offer the second mover ([2], p. 36).

Revealed altruism theory states that an individual's preferences can become more or less altruistic depending on the actions of another agent. Reciprocity, denoted as Axiom R, states that if a first mover provides a more generous opportunity set to the second mover then the second mover's preferences will become more altruistic towards the first mover. Data that support Axiom R come from many experiments $[2,10]$ including the triadic design experiment with the investment game reported by Cox [9]. In that experiment, Treatment $\mathrm{A}$ is the investment game and Treatment $\mathrm{C}$ takes the opportunity sets offered by first movers in Treatment $\mathrm{A}$ and randomly allocates them to second movers. Second movers in Treatment A know that they received a more generous opportunity set because the first mover was generous, whereas dictators in Treatment $\mathrm{C}$ know their paired subjects had no part in determining their opportunity sets. Support for Axiom R comes from significantly greater amounts returned by second movers in Treatment $A$ than in Treatment $C$ after taking into account the income effects of more generous opportunity sets [2]. Following evidence from investment game data, the similar PPT and CPT games should also follow Axiom R.

Axiom $\mathrm{S}$ is the element of revealed altruism theory that implies that the PPT and CPT games are not isomorphic. Axiom S distinguishes between acts of commission, which overturn the status quo, and acts of omission which uphold the status quo. The status quo is defined by the opportunity set determined by the initial endowments. A first mover upholds the status quo by offering the second mover the opportunity set defined by the initial endowment and overturns the status quo by offering any other opportunity set. Axiom S states that if the decision made by a first mover overturns the status quo then the reciprocal response, for individuals with preferences consistent with Axiom $\mathrm{R}$, will be stronger than when the status quo is upheld.

The collections of opportunity sets that the first mover can offer the second mover are identical in the PPT and CPT games but the status quo set determined by the endowments is different. The opportunity set determined by the endowments in the PPT game is the least generous opportunity set a first mover can offer in the PPT game because it provides the second mover only the opportunity to share her own \$ 10 private property endowment with the first mover. Each additional dollar that the first mover sends to the second mover in the PPT game provides the second mover with a yet more generous opportunity set. In contrast, the opportunity set determined by the endowments in the CPT game is the most generous opportunity set a first mover can offer in the CPT game because it provides the second mover with the opportunity to allocate $\$ 40$ between the two players. Each additional dollar that the first mover withdraws from the joint decision fund in the CPT game provides the second mover with a yet less generous opportunity set. To uphold the status quo set the first mover must send nothing to the second mover in the PPT game and withdraw nothing from the joint fund in the CPT 
game. A first mover overturns the status quo opportunity set in the PPT game by sending any positive amount. A first mover overturns the status quo opportunity set in the CPT game by withdrawing any positive amount.

A second mover with preferences consistent with Axioms $\mathrm{R}$ and $\mathrm{S}$ will care about how the opportunity set actually chosen by the first mover compares to the entire collection of opportunity sets the first mover could have chosen and also how the chosen set compares to the status quo opportunity set. Second movers will respond more altruistically towards first movers who overturn the status quo in the PPT game by sending $1,2,3, \ldots$, or 10 dollars, respectively, than they do to first movers who withdraw $9,8,7, \ldots$, or 0 dollars, respectively, in the CPT game. Also, second movers will respond less altruistically towards first movers who overturn the status quo in the CPT game by withdrawing 1 , 2 , $3 \ldots$ or 10 dollars, respectively, than to first movers who send $9,8,7 \ldots$ or 0 dollars, respectively, in the PPT game. The prediction is that second mover generosity will be lower in the CPT game than in the PPT game for any pair of choices in which the first mover sends $\pi$ in the PPT game and withdraws $10-\pi$ (i.e. leaves $\pi$ ) in the CPT game.

The null hypothesis $H_{o}^{S}$ about second mover play is consistent with economic man theory and popular models of (unconditional) social preferences [4-7]. ${ }^{1}$

$H_{o}^{S}$ : For any given number of dollars sent (in the PPT game) or left (in the CPT game), a second mover will return or allocate the same amount to the first mover in the PPT and CPT games.

The alternative hypothesis $H_{a}^{S}$ is consistent with revealed altruism theory [2].

$H_{a}^{S}$ : For any given number of dollars sent (in the PPT game) or left (in the CPT game), a second mover will return or allocate a larger amount to the first mover in the PPT game than in the CPT game.

Revealed altruism theory provides a theory of unconditional other-regarding preferences and a theory of reciprocity for second movers. One can, however, use that theory as a basis for conjectures about first mover play in the PPT and CPT games. Suppose some first movers anticipate that second movers have preferences consistent with a strict preference version of Axiom S. How would this affect their decisions? If a first mover is not comfortable with fully trusting the second mover, then he may wish to send only part of the endowment of \$ 10 in the PPT game (withdraw less than \$ 10 in the CPT game). Sending an amount less than \$ 10 in the PPT game may disappoint the second mover but may still make her happy because the status quo was even less generous. Withdrawing any positive amount in the CPT game may not only disappoint the second mover but may anger her because the status quo determined by the endowments was more generous. At the extreme, in the CPT game the second mover may decide to punish the first mover for withdrawing anything by leaving none of the

\footnotetext{
${ }^{1}$ Other papers have developed models of "player types" [11] or "player beliefs" [12, 13]. Given that "type" is a fixed characteristic of a player, a model of player types is consistent with $H_{o}^{S}$ but not $H_{a}^{S}$. Possible interpretations of player beliefs might be consistent with $H_{o}^{S}$ or with $H_{a}^{S}$.
} 
remaining joint fund to the first mover. If Type $\mathrm{X}$ players anticipate Type $\mathrm{Y}$ play consistent with Axioms $\mathrm{R}$ and $\mathrm{S}$, then they may withdraw $\$ 0$ if they are ready to fully trust and $\$ 10$ if they are not. If the first mover partially trusts the second mover, but is afraid the second mover may also punish her for withdrawing, then she may withdraw either the maximum of $\$ 10$ or nothing. These extremes are traditionally interpreted as "no trust” and "full trust” although the latent levels of trust by first movers may be less extreme (because of the presence of altruism and/or the fear of punishment for partial trust). These conjectures suggest hypotheses about first mover play in the PPT and CPT games.

$H_{o}^{F}$ : The frequency distributions of numbers of dollars sent in the PPT game or left in the CPT game by first movers will be the same.

$H_{a}^{F}$ : First movers will be more likely to choose the extremes of "full trust" and "no trust" in the CPT game than in the PPT game.

\section{The Cox, Ostrom, Walker et al. Study}

The COW study supports Axiom R because second movers return (or allocate) more to first movers who send more (or withdraw less). But the COW data do not support Axiom S because second mover choices are not significantly different between the PPT and CPT games. Hypothesis tests reported in COW do not reject the hypothesis that the two games are isomorphic. This finding is consistent with the weak preference ordering contained in Axiom $S$ but it does not provide support for a strong

preference ordering. One of two possibilities can explain their results: (1) subjects have preferences consistent with Axiom R but not with a strict preference version of Axiom S; or (2) this particular environment and pair of games did not elicit latent preferences consistent with a strict preference version of Axiom S. In the spirit of the second explanation we change the environment by adding saliency to private and common property ownership. Specifically, we ask if strengthening property entitlements will reveal preferences that are consistent with a strict preference version of Axiom S and lead to behavioral differences between the private and common property trust games.

\section{Stronger Property Right Entitlements}

In typical experiments, monetary endowments are used as resources or property that subjects use to make purchases, transfers, and other decisions. More often than not, monetary endowments are given to subjects simply for participating in the experiment. In other words they receive "house money" from the experimenter's research budget and are asked to make decisions with that money. Subjects could treat this "house money" differently than if the same money came from their regular income [14]. Milton Friedman's permanent income (PI) hypothesis states that subjects who prefer to smooth lifetime consumption will have a lower marginal propensity to consume a one-time gain in income [15]. Although some subjects participate in multiple experiments, experiment house money is not a regular source of income. Some studies have found that unexpected one-time gains encourage risk taking with the new money [16-20]. However, Clark [14] looked for "house money" effects in the voluntary-contributions mechanism (VCM) public good game and found none, so the "house money" effect is not a robust phenomenon. 
Why may property right entitlements not be strong enough already? If subjects regard their endowments as house money, then they may not care about the distinction between private property and common property. If this is true, then property ownership is not salient to the subjects. One way to strengthen entitlements and make property ownership salient is to have subjects earn their private or common property endowments.

How might earning endowments create a stronger sense of entitlement? Subjects must bear more effort cost in obtaining the property than the usual costs of showing-up and devoting time to the experiment, which can foster a stronger attachment to the property. This could motivate subjects' selfish tendencies to ensure they get the most out of the effort they invested in the game. It could also strengthen subjects' preferences for fairness or their risk preferences could change. Once the property has been earned all costs to obtain it should be considered sunk costs. Whether or not subjects ignore this sunk cost is an empirical question. Daniel Friedman [21] tested to see if subjects commit the sunk cost fallacy under a variety of different settings, but surprisingly found very few cases where they did.

Another convention is to randomly assign subjects to roles with symmetric entitlements. Cherry et al. [22] compared decisions made with unearned endowments in a dictator game baseline to a treatment with earned endowments. Low-stakes (high-stakes) endowments of \$ 10 (\$ 40) were earned by dictators answering less than 10 (10 or more) questions correctly on a quiz. Non-dictators had \$ 0 endowments and had no opportunity to take the quiz so entitlements were asymmetric. The percentage of dictators who transferred \$ 0 to the non-dictator increased from 19\% (15\%) in the low-stakes (high-stakes) baseline to $79 \%$ (70\%) in the earned endowments treatment [22]. Fahr and Irlenbusch [23] looked at the effect of the relative strength of property rights between the first mover and second mover in the trust game. There were three treatments defined by whether the first mover, second mover, or both had to crack walnuts to play the trust game. If required to crack walnuts, subjects had to collect $150 \mathrm{~g}$ of walnut kernels in about 30 minutes to earn the right to play. They found that the second movers were more generous towards first movers when the first movers worked and even more generous when the first movers worked and second movers did not work. First mover decisions were similar across treatments. Hoffman et al. [24] tested the effects of allowing subjects to earn the right of playing first mover in the ultimatum game by scoring high on a general knowledge quiz. They found that first movers offered smaller splits to the second movers, who were less likely to reject the offers, than in the baseline treatment in which subjects were randomly assigned to the first mover and second mover roles.

Since there is evidence that using earned rather than unearned entitlements to endowments or player roles has an effect in games similar to the COW experiment, we ask whether adding stronger private and common property entitlements affects behavior differently in the PPT and CPT games. Entitlements will be symmetric, and this will be implemented by having all players perform the same effort task. 


\section{Experiment Design}

The key design departure of this study from the COW study is the addition of the real effort task. This also required a switch from the hand-run procedure in COW to a computer-run experiment to save time needed for subjects to perform the real effort task. ${ }^{2}$ The substantive content of the computerized decision forms is identical to that in the COW study. Subject instructions are available on the web page of the abstract of the paper. Undergraduate students at Georgia State University were recruited by e-mail using the Experimental Economics Center (ExCEN) recruiter software. The experiment was run using a double-blind payoff protocol which prevents the subjects and experimenters from being able to personally identify any subject's decisions and payments. ${ }^{3}$ After signing in, subjects entered the ExCEN computer lab and began reading instructions for the real effort task.

The real effort task was intended to give subjects a stronger sense of entitlement to their private property or common property endowment. Subjects had to meet a performance quota to earn their endowments, which they were told would be used in the next part of the experiment. Subjects were also told in advance that if their quota was not met then they would be paid their show-up fee of $\$ 5$ and asked to leave the experiment without participating in the decision task.

Figure 1. Computer screenshot of the real effort task.

\section{The Whack-A-Mole Game!}

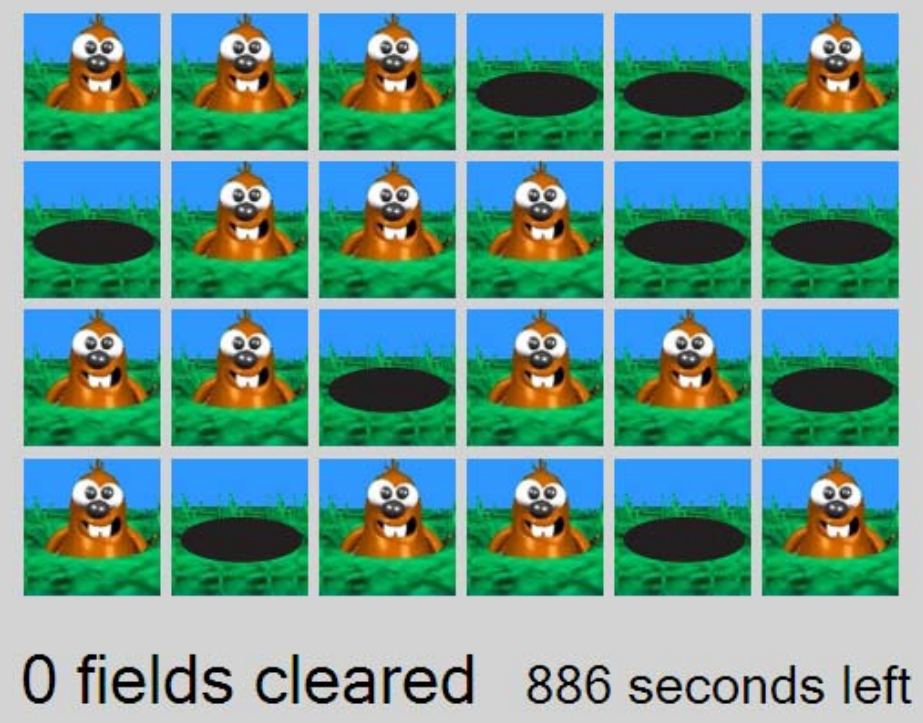

The real effort task was called the "whack-a-mole game.” Figure 1 shows a typical screen subjects would see during the game. There is a 6 by 4 grid of moles and holes on the field. Each time the

\footnotetext{
${ }^{2}$ The computer-run procedure was programmed using the Visual Basic Express 2008 Edition software.

${ }^{3}$ The original investment game experiment reported by Berg et al. [8], as well as the triadic design experiment reported by Cox [9] and the COW study [1] underlying the present paper, all used double blind payoffs. This type of payoff protocol has also been used in many other fairness game experiments.
} 
subject mouse-clicked a mole picture the picture box would show a hole picture. If the subject clicked on a hole picture nothing would happen. The object of the game is to mouse-click all of the moles until the field is clear of moles (there is only a field of holes). Once a field is cleared the computer generates a new field of moles. Each picture box has an equal probability of being a mole picture or a hole picture, so fields are half full of moles on average. ${ }^{4}$ The performance quota required the subject to clear a pre-specified number of fields within an announced time limit. Subjects had to meet the quota to earn the endowments that were used in the PPT or CPT game. After the time ran out for the whack-a-mole game anyone who did not meet the quota was paid \$ 5 and asked to leave. ${ }^{5}$

Subjects were told that by meeting the performance quota they would earn an endowment to be used in the next part of the experiment. The decision task was revealed after the whack-a-mole stage was finished. In Treatment CH1, subjects had to clear 120 mole fields in 15 minutes to earn their \$ 10 private endowments for the PPT game. In Treatment CH2, subjects had to clear 120 mole fields in 15 minutes to earn an endowment that was combined with that of another subject who met the quota and placed into a joint decision fund worth \$ 40 to be used in the CPT game. Once the subjects who did not fulfill the quota left, the remaining subjects were handed instructions for the PPT game or the CPT game.

Treatment CH1 implements the PPT game with the strategy response mode for second movers whereas treatment $\mathrm{CH} 2$ uses strategy responses in the CPT game. Treatment $\mathrm{CH} 3, \mathrm{CH} 4$, and $\mathrm{CH} 5$ use sequential responses for first and second movers. Treatment $\mathrm{CH} 3$ is a PPT game whereas treatments $\mathrm{CH} 4$ and $\mathrm{CH} 5$ are CPT games.

For both PPT and CPT games subjects were randomly paired as Type X and Type Y players. After reading the instructions and listening to a scripted explanation, each subject chose a sealed envelope containing a numbered mailbox key from a box containing identical envelopes. Subjects were told that the number on the mailbox key was their private identification number. They were told the numbered key would open a numbered mailbox containing their earnings from the decision-making game plus their show-up fee of $\$ 5$. Subjects collected their earnings one at a time, in private, and subsequently left the laboratory.

Table 1. Summary of treatments, sample sizes, and subjects' earnings.

\begin{tabular}{lccc}
\hline Treatment & Number of Subjects & Average \$ X Earned & Average \$ Y Earned \\
\hline COW1 (PPT) & 68 & 11.00 & 20.29 \\
COW2 (CPT) & 68 & 12.12 & 20.85 \\
CH1 (PPT) & 64 & 12.72 & 18.53 \\
CH2 (CPT) & 62 & 12.84 & 21.68 \\
CH3 (PPT) & 56 & 11.84 & 17.66 \\
CH4 (CPT) & 64 & 10.87 & 18.77 \\
CH5 (CPT) & 64 & 10.86 & 18.83 \\
\hline
\end{tabular}

\footnotetext{
${ }^{4}$ Each subject faced the same fields in the same sequence because all subjects' computers started with the same probability generating seed.

${ }^{5}$ If only an odd number of subjects met the performance quota, then the subject who was closest to meeting the performance quota was allowed to participate in the decision task because that task requires an even number of subjects.
} 
Table 1 summarizes all treatments, sample sizes, and average salient payoffs received by subjects. (The salient payoff amounts in Table 1 do not include the $\$ 5$ show-up fee.) The numbers of pairs of subjects are one-half the numbers in the second column. The treatments were implemented with a between-subjects protocol (i.e., no subject participated in more than one treatment).

\section{Strategy Method Protocol Treatments}

The COW study used a sequential move protocol to elicit first mover (Type $\mathrm{X}$ ) and second mover (Type Y) decisions. The difficulty in testing Axiom S using the sequential move protocol is that only one Type $\mathrm{Y}$ decision is made, and the potential responses to other opportunity sets the Type $\mathrm{X}$ player could have offered are not observed. Type $\mathrm{X}$ decisions could be distributed such that all possible decisions are observed frequently or decisions could be clustered. The latter case would make a direct test of Axiom $S$ require a very large sample under the sequential move protocol. The strategy method protocol offers the benefit of making all potential responses observable. It does this by asking a Type Y player to submit a planned response for each possible decision by a Type X player.

There are some potential problems with using the strategy method protocol. First is the reduction in incentives for Type $\mathrm{Y}$ players. Type $\mathrm{Y}$ players now have to make multiple potentially binding responses, yet only one decision determines their payoffs in the end. Their decision-making costs increase but their expected rewards do not. There is also a potential "hot" versus "cold” effect. A Type $\mathrm{Y}$ response in the sequential move protocol is considered "hot" because it is potentially more emotional for the Type Y player to learn the Type X player's decision, and how the decision affects their opportunities, before responding. The strategy method protocol is considered "cold" because a Type Y subject submits a planned response without knowing the Type $\mathrm{X}$ decision beforehand. There is mixed evidence on the significance of hot versus cold responses. Three studies do not find a hot versus cold effect [25-27] while two studies do find an effect [28,29].

Treatments $\mathrm{CH} 1$ and $\mathrm{CH} 2$ use the strategy method protocol to elicit Type Y responses, which requires 11 decisions. After the Type $\mathrm{X}$ and Type $\mathrm{Y}$ subjects in a pair make their decisions, the actual Type $\mathrm{X}$ decision makes the associated Type $\mathrm{Y}$ response to that decision binding and the game is played out to determine the money payoffs to the subjects. Figure 2 shows a screen shot of the Type $\mathrm{Y}$ player's decision table for the PPT game with the strategy method protocol. The rows are organized by the Type X person's potential actions in column A, with the first row representing the status quo. A subject enters an amount in each row of column C. The decisions can be entered in any order and changed at will up until the time the subject clicks on the Submit Decision Table button. The computer calculates an amount for a row in column $\mathrm{D}$ after a value is entered in that row of column $\mathrm{C}$. The decision table for the CPT game is similar except the Type $\mathrm{X}$ player withdraws rather than sends so the values in column B decrease from (the status quo amount) \$ 40 to \$ 10 . 
Figure 2. Type Y decision screen for the strategy method protocol.

\begin{tabular}{|c|c|c|c|}
\hline Column A & Column B & Column $\mathrm{C}$ & Column D \\
\hline $\begin{array}{l}\text { If the Paired Type } X \\
\text { Person Sends }\end{array}$ & $\begin{array}{c}\text { Then the Total Fund } \\
\text { Value is }\end{array}$ & $\begin{array}{c}\text { Amount You Wish to } \\
\text { Send to the Type } X \\
\text { Person }\end{array}$ & $\begin{array}{c}\text { Amount You Wish to } \\
\text { Keep }\end{array}$ \\
\hline 0 & $\$ 10.00$ & $\$ \times \times \propto$ & \$Y.YY \\
\hline 1 & $\$ 13.00$ & $\$ \times \times \propto$ & \$YYY \\
\hline 2 & $\$ 16.00$ & $\$ \times \times \times$ & \$Y.YY \\
\hline 3 & $\$ 19.00$ & $\$ \times \times \times$ & \$Y.YY \\
\hline 4 & $\$ 22.00$ & $\$ \times \times \times$ & \$Y.YY \\
\hline 5 & $\$ 25.00$ & $\$ \times \times \propto$ & \$YYY \\
\hline 6 & $\$ 28.00$ & $\$ \times \times \times$ & \$YYY \\
\hline 7 & $\$ 31.00$ & $\$ \times \times \propto$ & \$Y.YY \\
\hline 8 & $\$ 34.00$ & $\$ \times \times \propto$ & SY.YY \\
\hline 9 & $\$ 37.00$ & $\$ \times \times \propto$ & \$Y.YY \\
\hline 10 & $\$ 40.00$ & $\$ \times \times \propto$ & \$Y.YY \\
\hline \multicolumn{4}{|c|}{ Submit Decision Table } \\
\hline
\end{tabular}

126 undergraduate students from Georgia State University participated in Treatments CH1 and CH2 in four sessions. ${ }^{6}$ Treatment CH1 (the PPT game) was conducted in two sessions and, in total, 32 Type $\mathrm{X}$ subjects sent on average \$ 5.63 and 32 Type Y subjects returned on average \$ 6.96. Treatment CH2 (the CPT game) was also conducted in two sessions and, in total, 31 Type $\mathrm{X}$ subjects left, on average, \$ 7.26 and 31 Type Y subjects returned, on average, \$ 5.82. These figures are for all strategy responses by Type Y subjects. Table A1 in the appendix shows the summary data for Treatments $\mathrm{CH} 1$ and $\mathrm{CH} 2$ using realized subject payoffs. ${ }^{7}$

Figure 3 compares the distributions of Type $\mathrm{X}$ decisions for the two games. For the PPT game there are modes at 0,3 , and 10 dollars sent, and the distribution is $\mathrm{W}$-shaped with a fat right tail at 10 dollars sent. For the CPT game there are modes at 0, 5, and 10 dollars left, and the distribution is J-shaped with more than half of the subjects choosing not to withdraw anything.

\footnotetext{
${ }^{6} 126$ subjects attended these sessions. One subject failed to meet the mole quota in the last session for Treatment CH2. The subject was allowed to participate because an even number of subjects was needed to generate unique Type X and Type $\mathrm{Y}$ pairings.

${ }^{7}$ The \$ Y Returned and \$ Y Earned figures in appendix Table A1 are determined by the single decision for each Type Y subject that was selected by the actual Type $\mathrm{X}$ subject's decision.
} 
Figure 3. Comparison of Type X data for $\mathrm{CH} 1$ and $\mathrm{CH} 2$.

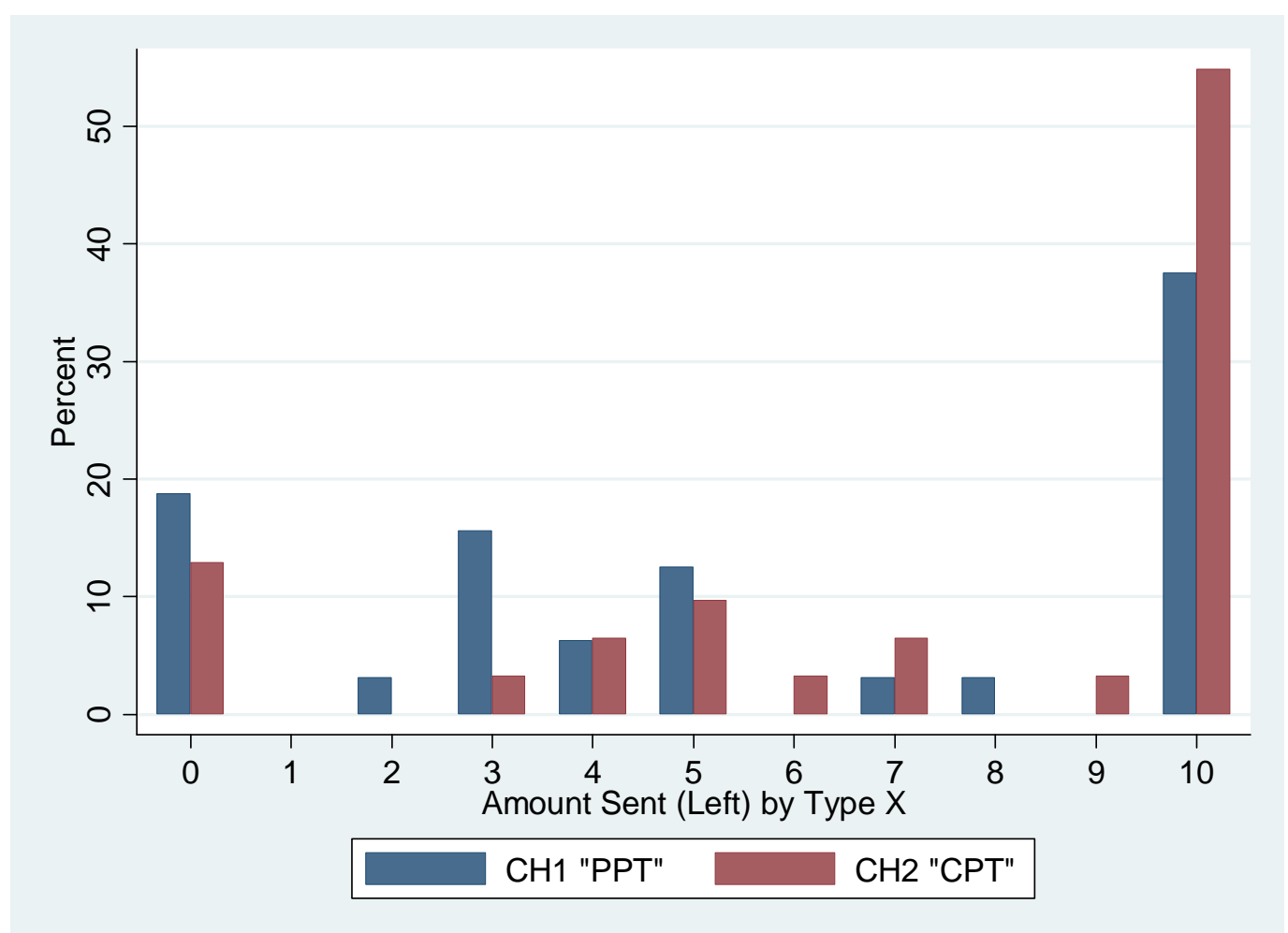

Table 2 shows the results of parametric and nonparametric tests of Type X subject data. The mean number of dollars left in the CPT game is greater than the mean number of dollars sent in the PPT game and the difference is significant according to the t-test. The distributions of amounts sent by Type $\mathrm{X}$ subjects in the PPT and CPT games are not significantly different according to the Mann-Whitney and Kolmogorov-Smirnov tests.

Table 2. Parametric and nonparametric tests of Type X data for $\mathrm{CH} 1$ and $\mathrm{CH} 2$.

\begin{tabular}{llll}
\hline & Parametric Test & \multicolumn{2}{c}{ Nonparametric Tests } \\
\hline Test & $\begin{array}{l}\text { Means Test } \\
(\mathrm{t}-\mathrm{t} \text { est })\end{array}$ & $\begin{array}{l}\text { Mann-Whitney Test } \\
\text { (Rank Sum) Test }\end{array}$ & Kolmogorov-Smirnov Test \\
\hline Null Hypothesis & $\mathrm{CH} 1=\mathrm{CH} 2$ & $\mathrm{CH} 1=\mathrm{CH} 2$ & Distributions are Equal \\
\hline Test Statistic & $\mathrm{t}=-1.7088$ & $\mathrm{z}=-1.692$ & $\mathrm{D}=0.2399$ \\
& $\begin{array}{l}\operatorname{Pr}(|\mathrm{T}|>|\mathrm{t}|)=0.0924 \\
\operatorname{Pr}(\mathrm{T}<\mathrm{t})=0.0462 *\end{array}$ & $\operatorname{Pr}(\mathrm{CH} 1>\mathrm{CH} 2)=0.0906$ & Exact $\mathrm{p}$-value $=0.256$ \\
\hline
\end{tabular}

${ }^{*} p<0.05$

The most straightforward test of hypothesis $H_{o}^{F}$ is a two sample proportions test of the distributions of Type X responses across the 11 possible choices in the PPT and CPT treatments. This test poses the question of whether the differences in empirical frequencies shown in Figure 3 are statistically significant. This test is reported in Table A2 in the appendix. There is only one proportion (for amount 
sent or left equal to 3) that is significantly different between the PPT and CPT data at 5 percent. The absence of significance for the proportions at "no trust" and "full trust" means that the data fail to reject hypothesis $H_{o}^{F}$.

We now turn our attention to second mover (Type Y) data. There are 352 and 341 Type Y decisions made in Treatments $\mathrm{CH} 1$ and $\mathrm{CH} 2$, respectively. Each subject in each treatment makes 11 decisions. There is no reason to assume independence of an individual's decisions. Our data analysis responds to this feature of the data in two ways. We report tests based on average responses across subjects to each amount that first movers could send. These average responses are independent across the 11 amounts that a first mover can send. The other way we analyze the data is with a random effects tobit estimation strategy in which an individual subject is a "panel."

Averaging the responses across second movers for each amount that can be sent by a first mover produces the variables reported in Figure 4 for the PPT and CPT treatments. The Type Y average across subjects is higher in the PPT treatment than the CPT treatment for all Type X choices except the extremes of 0 and 10 .

Figure 4. Comparison of average Type $\mathrm{Y}$ response data for $\mathrm{CH} 1$ and $\mathrm{CH} 2$.

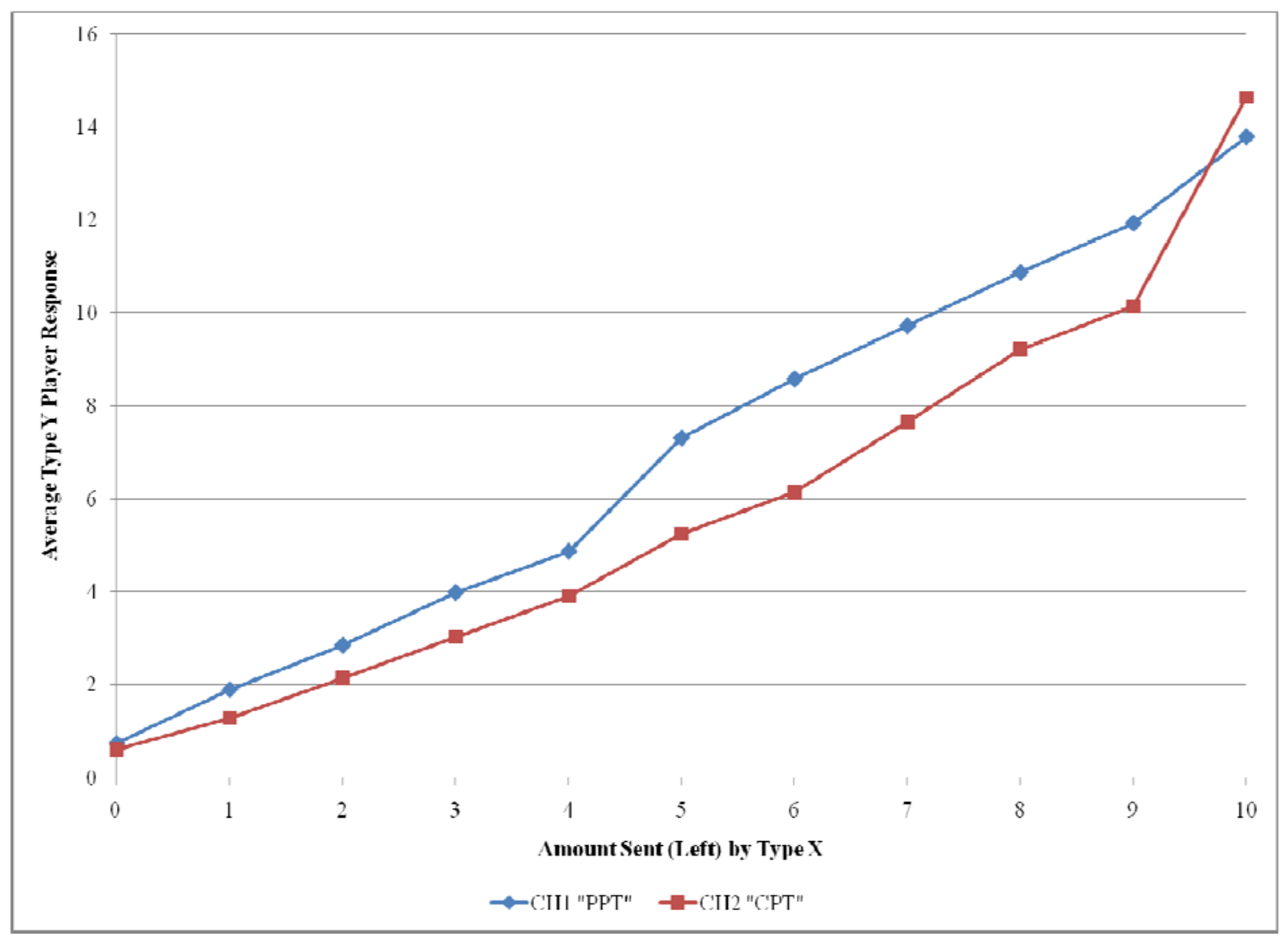

Table 3 reports results from a t-test and a Wilcoxon test for matched pairs. Both tests yield a highly significant difference between second mover responses in the PPT and CPT treatments. The null hypothesis $H_{o}^{S}$ that second movers (Type Y) will return the same amounts in the PPT and CPT games is rejected in favor of the alternative hypothesis $H_{a}^{S}$ (implied by Axioms $\mathrm{R}$ and $\mathrm{S}$ ) that second movers will return more in the PPT game. 
Table 3. Parametric and nonparametric tests of average Type Y response data for $\mathrm{CH} 1$ and $\mathrm{CH} 2$.

\begin{tabular}{lll}
\hline & Parametric Test & Nonparametric Test \\
\hline Test & $\begin{array}{l}\text { Means Test } \\
\text { (t-test, paired data) }\end{array}$ & $\begin{array}{l}\text { Wilcoxon Matched-Pairs } \\
\text { Signed-Rank Test }\end{array}$ \\
\hline Null Hypothesis & $\mathrm{CH} 1=\mathrm{CH} 2$ & $\mathrm{CH} 1-\mathrm{CH} 2=0$ \\
\hline Test Statistic & $\mathrm{t}=3.85$ & $\mathrm{z}=2.578$ \\
& $\operatorname{Pr}(|\mathrm{T}|>|\mathrm{t}|)=0.0032^{* *}$ & $\operatorname{Pr}>|\mathrm{z}|=0.0099^{* *}$ \\
& $\operatorname{Pr}(\mathrm{T}>\mathrm{t})=0.0016^{* *}$ & \\
\hline
\end{tabular}

${ }^{* *} p<0.01$

This conclusion is also supported by the random effects tobit estimation with individual subject data that is reported in Table A3 in the appendix. The coefficient on the amount sent or left by Type $\mathrm{X}$ players is significantly positive, which provides support for Axiom R. The common property intercept and slope dummy variables are both significant, which provides support for Axiom S. The estimated parameter for the intercept dummy variable is negative whereas the parameter for the slope variable is positive. This is consistent with: (a) second movers' objection to any change, due to first movers' withdrawals, from the (most generous) feasible set determined by the $\$ 40$ common pool endowment; and (b) their willingness to reward first movers' relative restraint in choosing smaller withdrawals.

\section{Sequential Move Protocol Treatments}

Why does the real effort task provide significant support for Axiom S (i.e., rejection of the null hypothesis $\left.H_{o}^{S}\right)$ ? The real effort task may create a stronger sense of entitlement to the endowments. When the Type X player withdraws any positive amount in the CPT game she destroys property that is not just jointly owned but now the Type Y player may have a stronger sense of entitlement to the joint fund. In other words the real effort task may create entitlements which make the property right assignments salient enough to bring Axiom S preferences out of latency.

It is natural for one to ask whether rejection of the null hypothesis can be attributed to use of the real effort task or use of the strategy method. Both design changes may affect behavior. The real effort task makes property ownership more salient. The strategy method lowers incentives because Type Y subjects have to submit 11 decisions instead of one for the same expected payoff. To get more insight we conducted sequential move treatments with the real effort task.

The experiment design and procedures for our sequential move protocol treatments are similar to the COW study except there are stronger property right entitlements. In Treatment CH3, subjects had to clear 120 mole fields in 15 minutes to play the PPT game. In Treatment CH4, subjects had to clear 120 mole fields in 15 minutes to play the CPT game. In Treatment CH5, subjects had to clear 240 mole fields in 30 minutes to earn the endowment necessary to play the same CPT game played in Treatment $\mathrm{CH} 4$. Treatment $\mathrm{CH} 5$ was conducted to set the mole-whacking effort per dollar of endowment earned equal to that in Treatments $\mathrm{CH} 1$ and $\mathrm{CH}$. The potential final earnings are identical in all three treatments. 
184 undergraduate students from Georgia State University participated in Treatments CH3, CH4, and $\mathrm{CH} 5$ run in seven sessions. ${ }^{8} 56$ subjects participated in Treatment $\mathrm{CH} 3$, the PPT game with a 120 mole field task. Treatment CH3 generated 28 Type X decisions (an average of \$ 4.75 was sent) and 28 Type Y decisions (an average of \$ 6.59 was returned). Treatment CH4, the CPT game with a 120 mole-field quota, was conducted in three sessions that generated 32 Type $\mathrm{X}$ decisions (an average of \$ 5.28 was sent) and 32 Type Y decisions (an average of \$ 6.14 was returned). Treatment CH5, the CPT game with a 240 mole-field quota, was conducted in two sessions, which generated 32 Type X decisions (an average of $\$ 4.84$ was sent) and 32 Type Y decisions (an average of \$ 5.70 was returned). Table A4 in the appendix displays the summary statistics for these treatments.

Differences between Treatment CH4 and Treatment CH5 data are insignificant, so the Treatment $\mathrm{CH} 4$ and $\mathrm{CH} 5$ data are pooled in tests reported in the text. (The appendix tables report separate tests for $\mathrm{CH} 4$ and $\mathrm{CH} 5$ data.) 128 subjects participated in Treatments $\mathrm{CH} 4$ and $\mathrm{CH} 5$ combined, which generated 64 Type X decisions (an average of \$ 5.06 was left) and 64 Type Y decisions (an average of $\$ 5.92$ was returned). Table A5 in the appendix summarizes the pooled Type $\mathrm{X}$ and Type $\mathrm{Y}$ decisions from Treatments $\mathrm{CH} 4$ and $\mathrm{CH} 5$, the CPT game.

Figure 5 displays the distributions of Type $\mathrm{X}$ decisions in all three treatments. Treatment $\mathrm{CH} 4$, the PPT game, has a W-shaped distribution with modes at $0,4,5$, and 10 . Treatments $\mathrm{CH} 4$ and $\mathrm{CH} 5$, the CPT game treatments, both have U-shaped distributions with heavy modes at 0 and 10 . Type $\mathrm{X}$ decisions move to the extremes of "full trust" and "no trust" in the CPT game much more strongly than in the PPT game. This result is more pronounced in the sequential move protocol treatments than in the strategy method treatment (compare Figures 3 and 5).

The straightforward test of hypothesis $H_{o}^{F}$, the two sample proportions test of the distributions of Type $\mathrm{X}$ responses is reported in Table 4. This test poses the question of whether the differences in empirical frequencies shown in Figure 5 are statistically significant. CH3 has significantly lower proportions of observations at 0 and 10 than does pooled $\mathrm{CH} 4$ and $\mathrm{CH} 5$. In addition, $\mathrm{CH} 3$ has significantly higher proportions of observations at 4, 5, and 6 than does pooled $\mathrm{CH} 4$ and $\mathrm{CH} 5$. These test results support rejection of hypothesis $H_{o}^{F}$, that the empirical frequency distributions are the same for PPT and CPT games, in favor of the alternative hypothesis $H_{a}^{F}$ that subjects are more likely to choose "full trust" and "no trust" in the CPT game than in the PPT game. Table A6 in the appendix reports two sample proportions tests for $\mathrm{CH} 4$ and $\mathrm{CH} 5$ data separately; these tests support similar conclusions.

\footnotetext{
${ }^{8} 188$ subjects attended these sessions. However 4 subjects were asked to leave because they were unable to meet the mole quota in the last session of Treatment $\mathrm{CH} 4$. 3 of the 4 subjects could not meet the mole quota because the computer software shutdown during the middle of the task for these individuals. Since the subjects faced unusual circumstances, all 4 subjects were paid \$ 15 in private for participation once they left the lab. Two subjects, in different sessions, did not meet the mole quota in time for Treatment CH3. These 2 subjects were allowed to play the PPT game because an even number of subjects was needed to generate unique Type $\mathrm{X}$ and Type $\mathrm{Y}$ pairings.
} 
Figure 5. Comparison of Type $\mathrm{X}$ data for $\mathrm{CH} 3$, $\mathrm{CH} 4$, and $\mathrm{CH} 5$.



Table 4. Proportions tests of Type X data for $\mathrm{CH} 3$ and pooled $\mathrm{CH} 4$ and $\mathrm{CH} 5$.

\begin{tabular}{ccclll}
\hline $\begin{array}{c}\text { Type X sent } \\
\text { or left }\end{array}$ & $\begin{array}{c}\text { Treatment CH3 } \\
\text { (PPT) }\end{array}$ & $\mathbf{N}$ & $\begin{array}{c}\text { Treatments } \\
\text { CH4 \& CH5 } \\
\text { (CPT) }\end{array}$ & N & $\begin{array}{l}\text { one-sided } \\
\text { p-value }\end{array}$ \\
\hline 0 & 0.1786 & 5 & 0.390625 & 25 & $0.0229^{*}$ \\
1 & 0.0357 & 1 & 0.0000 & 0 & 0.0642 \\
2 & 0.0357 & 1 & 0.0625 & 4 & 0.301 \\
3 & 0.1071 & 3 & 0.03125 & 2 & 0.0698 \\
4 & 0.1429 & 4 & 0.015625 & 1 & $0.0066^{* *}$ \\
5 & 0.1429 & 4 & 0.03125 & 2 & $0.023^{*}$ \\
6 & 0.1071 & 3 & 0.015625 & 1 & $0.0238^{*}$ \\
7 & 0.0357 & 1 & 0.0000 & 0 & 0.0642 \\
8 & 0.0000 & 0 & 0.0000 & 0 & $\ldots$ \\
9 & 0.0000 & 0 & 0.0000 & 0 & $\ldots$ \\
10 & 0.2143 & 6 & 0.453125 & 29 & $0.015^{*}$ \\
\hline
\end{tabular}

${ }^{*} p<0.05 \quad * * p<0.01$

Table A7 in the appendix reports additional parametric and non-parametric tests of Type X data. All t-tests fail to reject the null hypothesis that all treatments have similar mean amounts sent or left. The Mann-Whitney and Komolgorov-Smirnov tests imply that no distribution is significantly different from another in any treatment comparison. 
We now turn our attention to second mover (Type Y) data. Averaging the responses across Type Y subjects for each amount that can be sent by a Type $X$ subject produces the variables reported in Figure 6 for the PPT and CPT treatments. The dashed parts of the piecewise-linear graphs highlight parts of the response space for each treatment in which there are no observations because there were no Type $\mathrm{X}$ choices that could elicit Type $\mathrm{Y}$ responses. For example, the dashed segment of the blue (CH3) part of the display indicates that no Type X subject sent either \$ 8 or \$ 9 to a Type Y subject in the $\mathrm{CH} 3$ treatment. Note that the PPT (Treatment CH3) graph generally lies above the two CPT (Treatments $\mathrm{CH} 4$ and $\mathrm{CH} 5$ ) graphs and thus reveals a similar pattern to that shown in Figure 4 for the strategy method treatments. But the strategy method used in Treatments CH1 and CH2 elicited Type Y responses for all possible Type $\mathrm{X}$ choices whereas the sequential choice method used in Treatments $\mathrm{CH} 3, \mathrm{CH} 4$, and $\mathrm{CH} 5$ yields many "missing observations."

Figure 6. Comparison of average Type $\mathrm{Y}$ response data for $\mathrm{CH} 3, \mathrm{CH} 4$, and $\mathrm{CH} 5$.

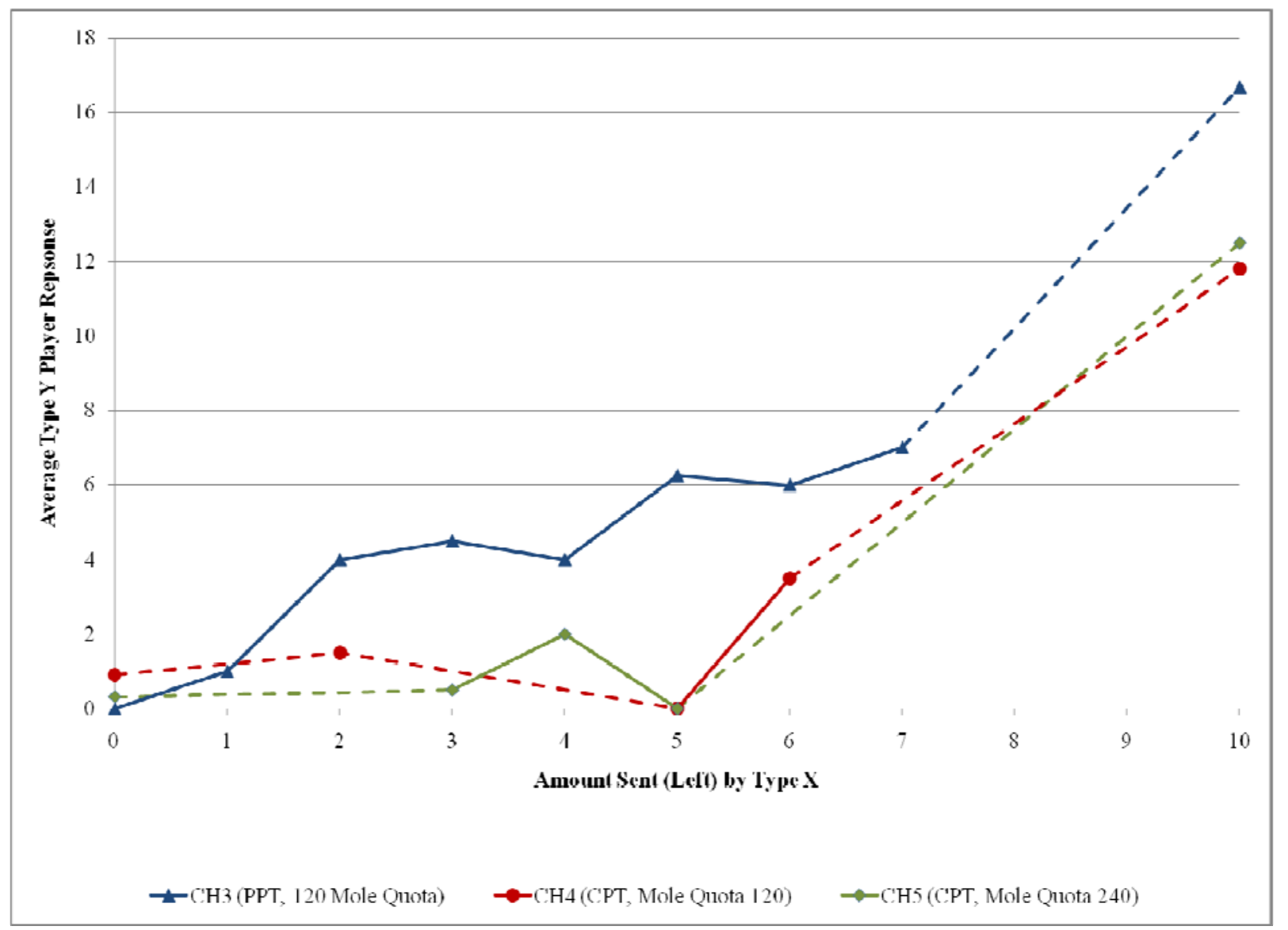

Table 5 reports results from a paired t-test and a Wilcoxon test for matched pairs, with the sequential response data, using the same approach used for strategy response data in Table 3. The p-value for the paired means t-test is 0.0051 and the p-value for the Wilcoxon matched pairs test is 0.0277. Similar to the strategy response data, tests of the sequential response data in Table 5 reject $H_{o}^{S}$ in favor of $H_{a}^{S}$. Table A8 in the appendix reports the same tests comparing Treatment CH3 to Treatments $\mathrm{CH} 4$ and $\mathrm{CH} 5$ separately; these tests support similar conclusions. 
Table 5. Parametric and nonparametric tests of avg. Type Y data for $\mathrm{CH} 3$ and pooled $\mathrm{CH} 4$ and CH5.

\begin{tabular}{lll}
\hline & Parametric Test & Nonparametric Test \\
\hline Test & $\begin{array}{l}\text { Means Test } \\
(\mathrm{t}-\mathrm{test} \text {, paired data })\end{array}$ & $\begin{array}{l}\text { Wilcoxon Matched-Pairs } \\
\text { Signed-Rank Test }\end{array}$ \\
\hline Null Hypothesis & $\mathrm{CH} 3=(\mathrm{CH} 4$ \& CH5 pooled $)$ & $\mathrm{CH} 3-(\mathrm{CH} 4$ \& CH5 pooled $)=0$ \\
\hline Test Statistic & $\mathrm{t}=2.491$ & $\mathrm{z}=1.461$ \\
& $\operatorname{Pr}(|\mathrm{T}|>|\mathrm{t}|)=0.0674$ & $\operatorname{Pr}>|\mathrm{z}|=0.0277^{*}$ \\
& $\operatorname{Pr}(\mathrm{T}>\mathrm{t})=0.0051^{* *}$ & \\
\hline${ }^{* p<0.05} \quad{ }^{* * p<0.01}$ & &
\end{tabular}

Table A9 in the appendix reports three tobit random effects estimations with Type Y return amounts as the dependent variable using data from Treatments $\mathrm{CH} 3, \mathrm{CH} 4$, and $\mathrm{CH} 5$. The independent variables include the Type $\mathrm{X}$ amount sent or left and CPT game intercept and slope dummy variables. The Type $\mathrm{Y}$ data are consistent with Axiom $\mathrm{R}$ as indicated by the “Type X Sent or Left” variable's statistical significance. The data do not support a strict preference version of Axiom $\mathrm{S}$, as indicated by the insignificance of both the CPT Intercept and Slope dummy variables. The lack of significance is likely coming from differences in the distribution of Type X decisions between the PPT and CPT games. Roughly $1 / 3$ of all Type $X$ decisions are to send $\$ 0$ or $\$ 10$ in the PPT game whereas to 2/3 of all Type $\mathrm{X}$ decisions are to withdraw $\$ 0$ or $\$ 10$ in the CPT game. The modal Type Y response to $\$ 0$ sent (\$10 withdrawn) is to return (leave) \$ . When $\$ 10$ are sent in the PPT game, the average return is \$16.67 (standard deviation 8.16), and when $\$ 0$ are withdrawn in the CPT game the average return is $\$ 12.14$ (standard deviation 8.23).

Tests of COW data with the same approach used in Table 5 and appendix Table A9 produce insignificant differences between the PPT and CPT treatments reported in the COW paper, confirming the tests results reported therein.

Support for both $H_{a}^{S}$ and $H_{a}^{F}$ is found in the sequential move protocol treatments. The entitlements appear to be not only salient enough to bring Axiom R and S preferences out of latency, but also salient enough for Type $\mathrm{X}$ players to anticipate these preferences and respond accordingly by choosing the extremes of "full trust" and "no trust."

\section{Conclusion}

We used a real effort task in which subjects had to meet a performance quota to earn the right to play in the private property trust (PPT) game or the common property trust (CPT) game. This was done to give the subjects a stronger sense of entitlement to their private or common property endowments and increase the saliency of property rights. We employ the strategy method in Treatments $\mathrm{CH} 1$ and $\mathrm{CH} 2$ in order to elicit the reciprocal second mover choice implications of first mover choices less frequently observed in the sequential move protocol. The strategy method protocol asks second movers to submit a planned response to each possible Type $\mathrm{X}$ choice. The strategy method treatments reveal that second movers allocate less to first movers in the CPT game than in the PPT game. This finding supports Axiom S from revealed altruism theory [2] and is inconsistent with the 
isomorphism of the PPT and CPT games implied by unconditional social preferences and economic man theories.

Treatments $\mathrm{CH} 3, \mathrm{CH} 4$, and $\mathrm{CH} 5$ employ the sequential move protocol. Type Y data from these treatments are consistent with data from the strategy method treatments. Support for Axiom S comes from paired t-tests and Wilcoxon matched-pairs tests but not from tobit estimations. Display of data from the two types of (strategy and sequential) treatments in Figures 4 and 6 suggests that the primary reason for the lower significance of the PPT vs. CPT treatment effect with the tobit estimation of sequential move protocol data can be attributed to "missing observations" relative to the strategy method protocol.

One notable finding is that first movers choose the extremes of "no trust" and "full trust" significantly more in the CPT game than in the PPT game for the sequential move protocol treatments. This did not occur for the strategy method protocol treatments. One possible explanation is related to the debated "hot" versus "cold" effect: perhaps first movers are more likely to anticipate and/or are more wary of "hot" responses (predicted for sequential responses) than "cold” responses (predicted for strategy responses) to their withdrawal of tokens in the CPT game. First mover expectations were not elicited, so this remains a conjecture.

Our data support the conclusion that the PPT and CPT games are not isomorphic under stronger property right entitlements. We find evidence of Type $\mathrm{Y}$ preferences that support Axiom S, which provides some insights into the differences in the need for trust and cooperation between private property environments and common property environments. We also provide further evidence that having subjects earn their endowments can be an important experimental design consideration in testing theory.

\section{Acknowledgements}

Financial support was provided by the National Science Foundation (grant number SES-0849590). Helpful comments and suggestions were provided by the referees. Helpful comments and suggestions were also provided by Vjollca Sadiraj, Ragan Petrie, and Lucy Ackert in development of the paper. Krawee “Kevin” Ackaramongkolrotn, Todd Swarthout, and Jason Delaney provided advice on experiment software development.

\section{Appendix}

Table A1. Summary data for strategy method treatments CH1 and CH2.

Treatment CH1: Private Property Trust Game (Mole Quota = 120)

\begin{tabular}{lllll}
\hline N-Pairs=32 & Mean & Std. Dev. & Minimum & Maximum \\
\hline Dollars X Sent & 5.63 & 3.94 & 0 & 10 \\
\$ Y Returned & 8.34 & 7.25 & 0 & 20 \\
\$ X Earned & 12.72 & 5.49 & 0 & 20 \\
\$ Y Earned & 18.53 & 8.87 & 0 & 40 \\
\hline
\end{tabular}


Table A1. Cont.

\begin{tabular}{|c|c|c|c|c|}
\hline \multicolumn{5}{|c|}{ Treatment CH2: Common Property Trust Game (Mole Quota = 120) } \\
\hline N-Pairs =31 & Mean & Std. Dev. & Minimum & Maximum \\
\hline Dollars X Left & 7.26 & 3.64 & 0 & 10 \\
\hline \$ Y Returned & 10.10 & 8.62 & 0 & 25 \\
\hline \$ X Earned & 12.84 & 6.49 & 0 & 21 \\
\hline \$ Y Earned & 21.68 & 7.56 & 10 & 40 \\
\hline
\end{tabular}

Table A2. Proportions tests of Type X data for strategy method treatments CH1 and CH2.

\begin{tabular}{clllll}
\hline $\begin{array}{c}\text { Type X sent } \\
\text { or left }\end{array}$ & $\begin{array}{c}\text { Treatment CH1 } \\
(\text { PPT })\end{array}$ & $\mathrm{N}$ & $\begin{array}{c}\text { Treatment CH2 } \\
(\mathrm{CPT})\end{array}$ & $\mathrm{N}$ & $\begin{array}{c}\text { one-sided } \\
\text { p-value }\end{array}$ \\
\hline 0 & 0.1875 & 6 & 0.1290323 & 4 & 0.2627 \\
1 & 0.0000 & 0 & 0.0000 & 0 & $\ldots$ \\
2 & 0.03125 & 1 & 0.0000 & 0 & 0.1606 \\
3 & 0.15625 & 5 & 0.0322581 & 1 & $0.0469^{*}$ \\
4 & 0.0625 & 2 & 0.0645161 & 2 & 0.4869 \\
5 & 0.125 & 4 & 0.0967742 & 3 & 0.3608 \\
6 & 0.0000 & 0 & 0.0322581 & 1 & 0.1529 \\
7 & 0.03125 & 1 & 0.0645161 & 2 & 0.2677 \\
8 & 0.03125 & 1 & 0.0000 & 0 & 0.1606 \\
9 & 0.0000 & 0 & 0.0322581 & 1 & 0.1529 \\
10 & 0.375 & 12 & 0.5483871 & 17 & 0.0837 \\
\hline
\end{tabular}

${ }^{*} p<0.05$

Table A3. Random effects tobit estimation with Type Y data for Treatments CH1 and CH2.

\begin{tabular}{ll}
\hline Number of Obs. & 693 \\
Number of Groups (Individuals) & 63 \\
\hline Constant Term & -2.674 \\
Type X Sent or Left & $(.055)$ \\
Common Property Intercept Dummy & 1.607 \\
& $(.000)^{* * *}$ \\
Common Property Slope Dummy & -4.49 \\
& $(.026)^{*}$ \\
Sigma_u & 0.302 \\
Sigma_e & $(.003)^{* *}$ \\
Rho & 7.440 \\
\hline
\end{tabular}

${ }^{*} p<0.05 \quad * * p<0.01 \quad * * * p<0.001$ 
Table A4. Summary data for sequential move protocol Treatments CH3, CH4, and CH5.

Treatment CH3: Private Property Trust Game (Mole Quota = 120)

\begin{tabular}{lllll}
\hline N-Pairs $=28$ & Mean & Std. Dev. & Minimum & Maximum \\
\hline \$ X Sent & 4.75 & 3.45 & 0 & 10 \\
\$ Y Returned & 6.59 & 7.43 & 0 & 20 \\
\$ X Earned & 11.84 & 5.36 & 0 & 20 \\
\$ Y Earned & 17.66 & 6.86 & 10 & 40 \\
\hline
\end{tabular}

Treatment CH4: Common Property Trust Game (Mole Quota = 120)

\begin{tabular}{lllll}
\hline N-Pairs = 32 & Mean & Std. Dev. & Minimum & Maximum \\
\hline \$ X Left & 5.28 & 4.70 & 0 & 10 \\
\$ Y Returned & 6.14 & 7.85 & 0 & 20 \\
\$ X Earned & 10.87 & 5.86 & 0 & 20 \\
\$ Y Earned & 18.77 & 10.53 & 0 & 40 \\
\hline
\end{tabular}

Treatment CH5: Common Property Trust Game (Mole Quota = 240)

\begin{tabular}{lllll}
\hline N-Pairs $=32$ & Mean & Std. Dev. & Minimum & Maximum \\
\hline \$ X Left & 4.84 & 4.78 & 0 & 10 \\
\$ Y Returned & 5.70 & 8.35 & 0 & 20 \\
\$ X Earned & 10.86 & 5.99 & 0 & 20 \\
\$ Y Earned & 18.83 & 10.27 & 0 & 40 \\
\hline
\end{tabular}

Table A5. Treatments CH4 and CH5 pooled common property trust game data.

\begin{tabular}{lllll}
\hline N-Pairs $=64$ & Mean & Std. Dev. & Minimum & Maximum \\
\hline \$ X Left & 5.06 & 4.71 & 0 & 10 \\
\$ Y Returned & 5.92 & 8.04 & 0 & 20 \\
\$ X Earned & 10.86 & 5.88 & 0 & 20 \\
\$ Y Earned & 18.80 & 10.32 & 0 & 40 \\
\hline
\end{tabular}

Table A6. Proportions tests of Type X data for CH3 and (non-pooled) CH4 and CH5.

\begin{tabular}{ccccclcll}
\hline $\begin{array}{c}\text { Type X sent } \\
\text { or left }\end{array}$ & $\begin{array}{c}\text { Treatment } \\
\text { CH3 } \\
(\mathrm{PPT})\end{array}$ & $\mathrm{N}$ & $\begin{array}{c}\text { Treatment } \\
\text { CH4 } \\
(\mathrm{CPT})\end{array}$ & $\mathrm{N}$ & $\begin{array}{l}\text { one- } \\
\text { sided } \\
\text { p-value }\end{array}$ & $\begin{array}{c}\text { Treatment } \\
\text { CH5 } \\
(\mathrm{CPT})\end{array}$ & $\begin{array}{l}\text { one- } \\
\text { sided } \\
\text { p-value }\end{array}$ \\
\hline 0 & 0.1786 & 5 & 0.34375 & 11 & 0.0744 & 0.4375 & 14 & $0.0157^{*}$ \\
1 & 0.0357 & 1 & 0.0000 & 0 & 0.1405 & 0.0000 & 0 & 0.1405 \\
2 & 0.0357 & 1 & 0.125 & 4 & 0.1059 & 0.0000 & 0 & 0.1405 \\
3 & 0.1071 & 3 & 0.0000 & 0 & $0.0287^{*}$ & 0.0625 & 2 & 0.2663 \\
4 & 0.1429 & 4 & 0.0000 & 0 & $0.0134^{*}$ & 0.03125 & 1 & 0.0593 \\
5 & 0.1429 & 4 & 0.03125 & 1 & 0.0593 & 0.03125 & 1 & 0.4617 \\
6 & 0.1071 & 3 & 0.03125 & 1 & 0.1199 & 0.0000 & 0 & $0.0287^{*}$ \\
7 & 0.0357 & 1 & 0.0000 & 0 & 0.1405 & 0.0000 & 0 & 0.1405 \\
8 & 0.0000 & 0 & 0.0000 & 0 & $\ldots$ & 0.0000 & 0 & $\ldots$ \\
9 & 0.0000 & 0 & 0.0000 & 0 & $\ldots$ & 0.0000 & 0 & $\ldots$ \\
\hline
\end{tabular}


Table A6. Cont.

\begin{tabular}{|c|c|c|c|c|c|c|c|c|}
\hline $\begin{array}{c}\text { Type X sent } \\
\text { or left }\end{array}$ & $\begin{array}{c}\text { Treatment } \\
\text { CH3 } \\
(\mathrm{PPT})\end{array}$ & $\mathrm{N}$ & $\begin{array}{c}\text { Treatment } \\
\text { CH4 } \\
(\mathrm{CPT})\end{array}$ & $\mathrm{N}$ & $\begin{array}{l}\text { one- } \\
\text { sided } \\
\text { p-value }\end{array}$ & $\begin{array}{c}\text { Treatment } \\
\text { CH5 } \\
\text { (CPT) }\end{array}$ & $\mathrm{N}$ & $\begin{array}{l}\text { one- } \\
\text { sided } \\
\text { p-value }\end{array}$ \\
\hline 10 & 0.2143 & 6 & 0.46875 & 15 & $0.0196 *$ & 0.4375 & 14 & $0.0336 *$ \\
\hline
\end{tabular}

$* p<0.05$

Table A7. Parametric and non-Parametric tests of Type X data for CH3, CH4, and CH5.

\begin{tabular}{|c|c|c|c|}
\hline & Parametric Test & \multicolumn{2}{|c|}{ Nonparametric Tests } \\
\hline Test & Means Test (t-test) & $\begin{array}{l}\text { Mann-Whitney Test } \\
\text { (Rank Sum) Test }\end{array}$ & $\begin{array}{l}\text { Kolmogorov-Smirnov } \\
\text { Test }\end{array}$ \\
\hline Null Hypothesis & $\mathrm{CH} 3=\mathrm{CH} 4$ & $\mathrm{CH} 3=\mathrm{CH} 4$ & Distributions are Equal \\
\hline Test Statistic & $\begin{array}{l}\mathrm{t}=-0.5031 \\
\operatorname{Pr}(|\mathrm{T}|>|\mathrm{t}|)=0.6168 \\
\operatorname{Pr}(\mathrm{T}<\mathrm{t})=0.3084\end{array}$ & $\begin{array}{l}\mathrm{z}=-0.245 \\
\operatorname{Pr}>|\mathrm{z}|=0.8065 \\
\operatorname{Pr}(\mathrm{CH} 3>\mathrm{CH} 4)=0.482\end{array}$ & $\begin{array}{l}\mathrm{D}=0.2545 \\
\text { Exact } \mathrm{p} \text {-value }=0.240\end{array}$ \\
\hline Null Hypothesis & $\mathrm{CH} 3=\mathrm{CH} 5$ & $\mathrm{CH} 3=\mathrm{CH} 5$ & Distributions are Equal \\
\hline Test Statistic & $\begin{array}{l}\mathrm{t}=-0.0878 \\
\operatorname{Pr}(|\mathrm{T}|>|\mathrm{t}|)=0.9303 \\
\operatorname{Pr}(\mathrm{T}<\mathrm{t})=0.4652\end{array}$ & $\begin{array}{l}\mathrm{z}=0.277 \\
\operatorname{Pr}>|\mathrm{z}|=0.7821 \\
\operatorname{Pr}(\mathrm{CH} 3>\mathrm{CH} 5)=0.520\end{array}$ & $\begin{array}{l}\mathrm{D}=0.2589 \\
\text { Exact } \mathrm{p} \text {-value }=0.224\end{array}$ \\
\hline Null Hypothesis & $\mathrm{CH} 3=\mathrm{CH} 4$ \& $\mathrm{CH} 5$ & $\mathrm{CH} 3=\mathrm{CH} 4$ \& $\mathrm{CH} 5$ & Distributions are Equal \\
\hline Test Statistic & $\begin{array}{l}t=-0.3559 \\
\operatorname{Pr}(|T|>|t|)=0.7230 \\
\operatorname{Pr}(T<t)=0.3615\end{array}$ & $\begin{array}{l}\mathrm{z}=0.018 \\
\operatorname{Pr}>|\mathrm{z}|=0.9858 \\
\operatorname{Pr}(\mathrm{CH} 3>\mathrm{CH} 4 \text { \& CH5 })= \\
0.501\end{array}$ & $\begin{array}{l}\mathrm{D}=0.2388 \\
\text { Exact } \mathrm{p} \text {-value }=0.181\end{array}$ \\
\hline Null Hypothesis & $\mathrm{CH} 4=\mathrm{CH} 5$ & $\mathrm{CH} 4=\mathrm{CH} 5$ & Distributions are Equal \\
\hline Test Statistic & $\begin{array}{l}\mathrm{t}=0.3692 \\
\operatorname{Pr}(|\mathrm{T}|>|\mathrm{t}|)=0.7132 \\
\operatorname{Pr}(\mathrm{T}>\mathrm{t})=0.3566\end{array}$ & $\begin{array}{l}\mathrm{z}=0.460 \\
\operatorname{Pr}>|\mathrm{z}|=0.6459 \\
\operatorname{Pr}(\mathrm{CH} 4>\mathrm{CH} 5)=0.531\end{array}$ & $\begin{array}{l}\mathrm{D}=0.938 \\
\text { Exact } \mathrm{p} \text {-value }=0.999\end{array}$ \\
\hline
\end{tabular}

Table A8. Parametric and nonparametric tests of avg. Type Y data for CH3, CH4, and CH5.

\begin{tabular}{lll}
\hline & Parametric Test & Nonparametric Test \\
\hline Test & $\begin{array}{l}\text { Means Test } \\
(\mathrm{t}-\text { test, paired data) }\end{array}$ & $\begin{array}{l}\text { Wilcoxon Matched-Pairs } \\
\text { Signed-Rank Test }\end{array}$ \\
\hline Null Hypothesis & $\mathrm{CH}=\mathrm{CH} 4$ & $\mathrm{CH}-\mathrm{CH} 4=0$ \\
\hline Test Statistic & $\mathrm{t}=2.491$ & $\mathrm{z}=1.761$ \\
& $\operatorname{Pr}(|\mathrm{T}|>|\mathrm{t}|)=0.0674$ & $\operatorname{Pr}>|\mathrm{z}|=0.0782$ \\
\hline Null Hypothesis & $\operatorname{Pr}(\mathrm{T}>\mathrm{t})=0.0337^{*}$ & $\mathrm{CH} 3-\mathrm{CH} 5=0$ \\
\hline Test Statistic & $\mathrm{CH} 3=\mathrm{CH} 5$ & $\mathrm{z}=1.069$ \\
& $\mathrm{t}=2.8957$ & $\operatorname{Pr}>|\mathrm{z}|=0.0796$ \\
\hline & $\operatorname{Pr}(|\mathrm{T}|>|\mathrm{t}|)=0.0443$ & \\
\hline
\end{tabular}

$* p<0.05$ 
Table A9. Random effects tobit estimations with Type $\mathrm{Y}$ data for Treatments CH3, $\mathrm{CH} 4, \mathrm{CH} 5$.

\begin{tabular}{llll}
\hline Regression & $(1)$ & $(2)$ & $(3)$ \\
\hline Data Set & Treatments CH3, & Treatments & Treatments \\
& CH4, and CH5 & CH3 and CH4 & CH3 and CH5 \\
\hline Number of Obs & 92 & 60 & 60 \\
Number of Groups (Individuals) & 92 & 60 & 60 \\
\hline Constant & -7.217 & -6.812 & -6.898 \\
& $(.033)$ & $(.032)$ & $(.033)$ \\
Type X Sent or Left & 2.335 & 2.291 & 2.301 \\
& $(.000)^{* * *}$ & $(.000)^{* * *}$ & $(.000)^{* * *}$ \\
CPT Intercept Dummy & -1.845 & -0.157 & -4.330 \\
& $(.662)$ & $(.970)$ & $(.354)$ \\
CPT Slope Dummy & -0.258 & -0.495 & -0.010 \\
& $(.672)$ & $(.423)$ & $(.987)$ \\
240 Mole Field-Quota & -0.927 & $\ldots$ & $\ldots$ \\
Sigma_u & $(.0707)$ & & \\
& $6.32 \mathrm{e}-09$ & $9.42 \mathrm{e}-09$ & $6.93 \mathrm{e}-10$ \\
Sigma_e & $(1.000)$ & $(1.000)$ & $(1.000)$ \\
& 8.33 & 7.758 & 7.879 \\
Rho & $(.000)^{* * *}$ & $(.000)^{* * *}$ & $(.000)^{* * *}$ \\
\hline
\end{tabular}

\section{References}

1. Cox, J.C.; Ostrom, E.; Walker, J.M.; Castillo, J.; Coleman, E.; Holahan, R.; Schoon, M.; Steed, B. Trust in Private and Common Property Experiments. Southern Econ. J. 2009, 75, 957-975.

2. Cox, J.C.; Friedman, D.; Sadiraj, V. Revealed Altruism. Econometrica 2008, 76, 31-69.

3. Hardin, G. The Tragedy of the Commons. Science 1968, 162, 1243-1248.

4. Fehr, E.; Schmidt, K.M. A Theory of Fairness, Competition, and Cooperation. Quart. J. Econ. 1999, 114, 817-868.

5. Bolton, G.E.; Ockenfels, A. ERC: A Theory of Equity, Reciprocity, and Competition. Amer. Econ. Rev. 2000, 90, 166-193.

6. Charness, G.; Rabin, M. Understanding Social Preferences with Simple Tests. Quart. J. Econ. 2002, 117, 817-869.

7. Cox, J.C.; Sadiraj, V. On Modeling Voluntary Contributions to Public Goods. Public Financ. Rev. 2007, 35, 311-332.

8. Berg, J.; Dickhaut, J.; McCabe, K. Trust, Reciprocity, and Social History. Game. Econ. Behav. 1995, 10, 122-142.

9. Cox, J.C. How to Identify Trust and Reciprocity. Game. Econ. Behav. 2004, 46, 260-281.

10. Cox, J.C.; Friedman, D.; Gjerstad, S. A Tractable Model of Reciprocity and Fairness. Game. Econ. Behav. 2007, 59, 17-45. 
11. Levine, D.K. Modeling Altruism and Spitefulness in Experiments. Rev. Econ. Dyn. 1998, 1, 593-622.

12. Dufwenberg, M.; Kirchsteiger, G. A Theory of Sequential Reciprocity. Game. Econ. Behav. 2004, 47, 268-298.

13. Rabin, M. Incorporating Fairness into Game Theory and Economics. Amer. Econ. Rev. 1993, 83, 1281-1302.

14. Clark, J. House Money Effects in Public Good Experiments. Exp. Econ. 2002, 5, 223-231.

15. Friedman, M. A Theory of the Consumption Function; Princeton University Press: Princeton, NJ, USA, 1957; pp. 1-260.

16. Arkes, H.R.; Joyner, C.A.; Pezzo, M.V.; Nash, J.G.; Siegel-Jacobs, K.; Stone, E. The Psychology of Windfall Gains. Organ. Behav. Hum. Decision Proc. 1994, 59, 331-347.

17. Battalio, R.C.; Kagel, J.H.; Jiranyakul, K. Testing Between Alternative Models of Choice Under Uncertainty: Some Initial Results. J. Risk Uncertainty 1990, 3, 25-50.

18. Keasey, K.; Moon, P. Gambling with the House Money in Capital Expenditure Decisions: An Experimental Analysis. Econ. Lett. 1996, 50, 105-110.

19. Thaler, R.H. Anomalies: Saving, Fungibility, and Mental Accounts. J. Econ. Perspect. 1990, 4, 193-205.

20. Thaler, R.H.; Johnson, E.J. Gambling with the House Money and Trying to Break Even: The Effects of Prior Outcomes on Risky Choice. Manag. Sci. 1990, 36, 643-660.

21. Friedman, D. Searching for the Sunk Cost Fallacy. Exp. Econ. 2007, 10, 79-104.

22. Cherry, T.; Frykblom, P.; Shogren, J. Hardnose the Dictator. Amer. Econ. Rev. 2002, 92, 1218-1221.

23. Fahr, R.; Irlenbusch, B. Fairness as a Constraint on Trust in Reciprocity: Earned Property Rights in a Reciprocal Exchange Experiment. Econ. Lett. 2000, 66, 275-282.

24. Hoffman, E.; McCabe, K.; Shachat, K.; Smith, V. Preferences, Property Rights, and Anonymity in Bargaining Games. Game. Econ. Behav. 1994, 7, 346-380.

25. Brandts, J.; Charness, G. Hot vs. Cold: Sequential Responses and Preference Stability in Experimental Games. Exp. Econ. 2000, 2, 227-238.

26. Cason, T.N.; Mui, V.-L. Social Influence in the Sequential Dictator Game. J. Math. Psychol. 1998, 42, 248-265.

27. Oxoby, R.J.; McLeish, K.N. Sequential Decision and Strategy Vector Methods in Ultimatum Bargaining: Evidence on the Strength of Other-regarding Behavior. Econ. Lett. 2004, 84, 399-405.

28. Brosig, J.; Weimann, J.; Yang, C.-L. The Hot Versus Cold Effect in a Simple Bargaining Experiment. Exp. Econ. 2003, 6, 75-90.

29. Casari, M.; Cason, T.N. The Strategy Method Lowers Measured Trustworthy Behavior. Econ. Lett. 2009, 103, 157-159.

(C) 2010 by the authors; licensee MDPI, Basel, Switzerland. This article is an open access article distributed under the terms and conditions of the Creative Commons Attribution license (http://creativecommons.org/licenses/by/3.0/). 